\title{
Explosion Accidents Evaluation of MV. Gili Cat II using Apollo Root Cause Analysis
}

\author{
Ricard Diago Sambuaga ${ }^{1, a, *}$, Trika Pitana ${ }^{1, b}$, Dwi Priyanta ${ }^{1, c}$ and Aleik Nurwahyudi ${ }^{2, d}$ \\ ${ }^{1}$ Department of Marine Engineering, Institut Teknologi Sepuluh Nopember Surabaya, Surabaya, \\ Indonesia \\ ${ }^{2}$ National Transportation Safety Committee, Ministry of Transportation, Jakarta, Indonesia \\ a.ricarddiagos@gmail.com,b.trika@its.ac.id,c.priyanta@its.ac.id,d. \\ aleiknurwahyudy@gmail.com \\ *corresponding author
}

Keywords: Apollo Root Cause Analysis (ARCA), Electrical System, Fuel Oil System, MV. Gili Cat II.

Abstract: According to the National Transportation Safety Committee (NTSC), the highest percentage of the accident (2007-March 2017) is fire or explosion (38\%). MV. Gili Cat II had been exploded on September 15th, 2016 at Padangbai port, Bali. Therefore, the accident investigation is to investigate what are root causes of this explosion. The investigation was utilizing Apollo Root Cause Analysis methodology. The research shows that the explosion was probably caused by - electrical wiring system, static electricity around the vessel's fuel tank and hull. Purposes of this study are to reanalyse the root cause of the explosions on the ship, to evaluate fuel oil and electrical system of outboard engines according to nonconventional vessel standard (NCVS). In addition, there is no earthing system of the vessel. It strongly indicating the presence of static electricity to reasonably take place. On the other hand, there was evidence showing fuel was spilled when refuelling. Other evidence showed that significant amount of fuel gas flow from leaking fuel line to the compartment below deck. The fuel tank's venting pipe was not following the appropriate standard and using inappropriate materials. Compartments below deck were not gas tight and only using a spot welding on the ship was found. Therefore, the following recommendations related to the Electrical system were proposed as follows: the earthing system should be fitted to prevent the presence of static electricity, the battery should be mounted properly to prevent movement of the battery which caused by the motion of the vessel. Besides, the following recommendations related to the Fuel oil system are material of flexible pipe is using SAE J 30 or equivalent, using an appropriate mechanism to fill the tank and done safely, and fuel tanks should be earthed.

\section{Introduction}

Safety of the ship is a very important issue on the maritime side. Big amount of ship accidents is one of the backgrounds why safety is very important. NTSC investigation showed that from $2007-$ March 2017 there have been total 77 accidents. The highest percentage of that accident is caused by fire or explosion ( $38 \%$ or 29 accidents) [1]. 
MV. Gili Cat II had been exploded on Thursday, September 15th, 2016. Ships were departed from Padangbai, Bali to Gili Trawangan, Lombok. There were 35 passengers on board when the ship exploded. An accident occurred at 09.35 near to Padangbai Port, Bali. From this accident, there were 2 passengers got fatalities [2].

From this accident, an investigation is needed. The investigation was carried by using Apollo Root Cause Analysis (ARCA) methodology. ARCA is recommended for event / incident-based items of complex and higher significance. This methodology is recommended because it provides a causal path to root causes, delineates evidence, and explains how solution prevent recurrence. To complete the ARCA, there are 4 steps that should be followed. Four steps that should be followed are: Define the problem, Create Reality or Cause-Effect Chart (Chart is created supported with evidence), Identify possible effective solution, implement the best solution and finalize the report [3].

Results of this analysis are the root cause of this case and solutions that can be implemented. Solutions or recommendations in this paper are based on non-conventional vessel standard (NCVS) (Chapter V - Machinery \& Electrical) especially on fuel oil system and electrical system.

The Contribution of this study is to provide recommendations for fuel oil system and electrical system of outboard engines. This paper could also be used for related parties to determine the act of prevention and mitigation of explosions on allied ships, especially for a ship that used outboard engines.

This paper is organized into five sections. The first section of this paper is about the background of the research. In the second section is about literature review. In the third section discuss accident description and ARCA-RealityCharting methodology. In the fourth section is about results of the investigation using ARCA and system recommendation (fuel oil system and electrical system). The last section is about conclusions of this case.

\section{Literature Review}

There are many tools or methods of root cause analysis to evaluating or analyse any cases, accidents, or etc. Apollo root cause analysis is one of the methods that can be implemented effectively in some cases [3].

ARCA methodology has been implemented by Gunawan, Rachmat [4] to analyzing the root cause of a leakage in the engine room of KM. Nusantara Akbar. The root cause of the leakage of the vessel was analysed.

Shell E\&P has adopted the ARCA methodology as a core RCA methodology. ARCA methodology could be used for any size and complexity of failure investigation in the company [5]. Reliability Engineer of BHP Billiton was using ARCA as a problem-solving. ARCA is a methodology that very specifics and simple to solve a problem. ARCA methodology gives some new way of thinking of some problem solving [5]. ARCA program (Realitycharting) is a very useful tool. It also allows a Lead Commissioning Technician at Siemens Ltd to present the information the client in a clear and professional manner [5].

The comparison between ARCA methods with the other RCA methods and tools is described Fig. 1. Based on the methodology comparison below, ARCA has the biggest score. It is because ARCA method defines the problem details, delineates evidence for each cause, also it helps to create RCA report easily, etc. 


\begin{tabular}{|c|c|c|c|c|c|c|c|c|}
\hline Method/Tool & Type & $\begin{array}{l}\text { Defines } \\
\text { Problem }\end{array}$ & $\begin{array}{l}\text { Defines } \\
\text { All Known } \\
\text { Causes }\end{array}$ & $\begin{array}{c}\text { Provides } \\
\text { ACausal } \\
\text { Path To } \\
\text { RootCauses }\end{array}$ & $\begin{array}{c}\text { Delineates } \\
\text { Evidence }\end{array}$ & $\begin{array}{l}\text { Explains How } \\
\text { Solutions } \\
\text { Prevent } \\
\text { Recurrence }\end{array}$ & $\begin{array}{l}\text { Easy To } \\
\text { Follow } \\
\text { Report }\end{array}$ & Score \\
\hline Events \& Causal Factors & Method & Yes & Limited & № & № & No & № & 1.5 \\
\hline Change Analysis & Tool & Yes & № & № & № & $\mathrm{N}_{0}$ & № & 1 \\
\hline Barrier Analysis & Tool & Yes & No & No & No & № & № & 1 \\
\hline Tree Diagrams & Method & Yes & № & № & № & NNo & № & 1 \\
\hline Why-Why Chart & Method & Yes & № & Yes & No & No & No & 2 \\
\hline Pareto & Tool & Yes & № & № & No & No & № & 1 \\
\hline Storytelling & Method & Limited & No & № & No & № & No & 0.5 \\
\hline Fault Tree & Method & Yes & Yes & Yes & No & Yes & № & 4 \\
\hline FMEA & Tool & Yes & № & Limited & No & Limited & No & 2 \\
\hline RealityCharting ${ }^{\circ}$ & Method & Yes & Yes & Yes & Yes & Yes & Yes & 6 \\
\hline
\end{tabular}

Figure 1: Comparison of Selected RCA Methods and Tools [3]

\section{Methodology}

The methodology of this paper is described in Fig. 2. The methodology of this paper is started by collecting data, then the data is processed into root cause analysis, and the last is giving some recommendation regarding the case. Collecting data that needed in this paper are the description, accident reports, general arrangement, and daily report of MV. Gili Cat II.

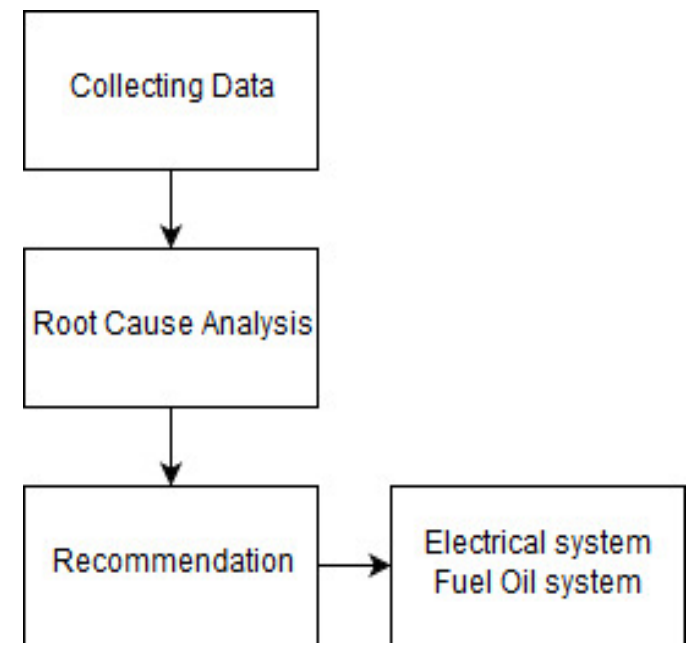

Figure 2: Research Methodology

The description and accident reports are used to create root cause analysis using ARCA methodology and then, the description, General Arrangement (GA), and daily reports are needed to creating Fuel Oil System (FOS) and Electrical System. There is some step to complete an ARCA method. ARCA steps consisted of Define the problem, creating a chart, identify a possible solution, implement the best solution, and finalize the report. A report in this paper will be created automatically.

The results of this analysis are: what are root causes of this problem, what are solutions that can be implemented, and how is the report of the analysis. The description, GA, and daily report are needed to support of system recommendation. Recommendations in this paper are based on NCSV 
(Chapter V - Machinery \& Electrical) and NFPA. After FOS and Electrical system recommendation already completed, it can be used to preventing similar case or it can be used for other parties.

\section{Objective Study}

\subsection{Explosion Chronology}

An accident occurred at 09.35 WITA near Padangbai Port, Bali. In this explosion accidents, there were 2 passengers got fatalities and some passengers got injuries.

\subsection{Gili Cat II Description}

MV. Gili Cat II is a passenger ship that serves from Padangbai (Bali) to Gili Trawangan (Lombok). This ship was constructed in Australia in 2001. The main material is using aluminum. In 2013, PT. Indonusa Segara Marine defined as companies that holding ISM certificates. It operated by PT. Samudera Ekspedisi Aman in 2014. General data of this ship is as follows:

- Length Overall : 11,69 m

- Breadth Molded : $3,42 \mathrm{~m}$

- Draught : $0,60 \mathrm{~m}$

- Depth :0,90 m

- Gross Tonnage : $6 \mathrm{~T}$

- Net Tonnage :-

- Type : Passenger Ship

- Flag : Indonesia

- Production Year : 2001

- Production Location : Australia

- Construction Material: Aluminum

This vessel can carry 35 passengers with 4 crews. It uses 3 units of outboard engines type Suzuki DF300 4 stroke types with the power of 300 HP. Ship engine configuration be able to provide power to the ship's speed reached to 45 knots in the maximum rotation. The average speed of this speed is 20-25 knots (Padangbai - Gili Trawangan can be reached within 1.5 hours). Gasoline is a fuel of these main engines, but in the last 3 months using a mixed fuel of gasoline and pertalite. Three ship propulsions unit (outboard engines) are coupled in series.

\section{Apollo Root Cause Analysis (ARCA)}

Root Cause Analysis is a wide variety method used to identify the causes of problems (tracing problem to their origin) and helps answer the question of why the problem happened in the first place, which in turn, and can help us to prevent the recurrence [3]. ARCA is recommended for event/incident-based items of complex and higher significance. There are many benefits using ARCA methodology:

1. Create a common reality: A RealityCharting is produced showing all the known causes and their inter-relationships.

2. Eliminating recurring problems: Identifying solutions that are within the organization's control, prevent recurrence and meet the organization's goals and objectives.

3. Get a defined result: The result in clear causal connections between your solutions and the defined problem. 
4. Address any size problem: scalable to any problem, large or small.

5. Eliminate assumption: scalable to any problem, large or small.

To complete the Apollo root cause analysis, there are 4 steps that should be followed. Before starting the first step, we should. Collect Information (drawing, picture, evidence preservation, and conduct interviewers, create a timeline of events, etc.). Four steps that should be followed are:

1. Define the problem in detail.

2. Create Cause-Effect Chart. The chart is created supported by evidence.

3. Identify possible effective solution.

4. Implement the best solution and finalize the report.

\section{Result and Discussion}

An initial stage of this paper is identifying documents that have been obtained. Those documents are the description, accidents report, GA, and daily report. That information can be used as evidence of this explosion.

Data is processed using ARCA methods. The first stage of ARCA method is defining the problem. It explaining the accident in detail, then proceed with the Create Chart. Creating chart must be made with the evidence that already exists. After creating a chart is complete, then continue with the Identify possible solution. At this stage, any solution is identified. It should be related to the case being dealt with. After identifying the possible solution has been completed then followed by implementing those solutions. Implementing best solution can be done through assessment solution. Assessment solution was performed to assess any solution that can be implemented in a related case.

\subsection{Root Cause Analysis}

The first stage of ARCA methodology defines the problem. Problem definition is explaining "what is the problem", when (date, time) the problem happens, where (location), significance. The detail root cause analysis of MV. Gili Cat II explosion is described in Figure 3. The author is classified each cause based on fire triangle theory and interview/discussion with the NTSC Investigator.

The second stage is determining the cause of the effect. Creating charts in ARCA methods have some fundamental elements. Fundamental elements include: ask "why" for each primary effect, Causes are consisting with condition and action, comment all causes with "the caused by", support all causes with evidence, and each caused path stop with "?" Or a reason for stopping. The explosion location is in below of ship deck. Location of the explosion is beside of the fuel tank. Explosion can happen caused by saturated gas are accumulated in that below deck. After saturated gas accumulated, then there is mixing gas between air (oxygen) and saturated gas (Fuel) and an Igniter. An explosion can happen because of these three elements. In this RCA, there is no any weight to create a ranking in each cause. It is because based on the ARCA methodology it did not tell to create any weight of each cause.

1. There are some conditions onboard that became the main cause of the explosion. Conditions that became the main cause of Igniter factor are:

- The bad Electrical wiring system

a) Tightening battery using a belt tied manually. In this condition, it evident with battery compartments cannot prevent movement due to the motion of the vessels. 
b) Wood boards and sponges used as a prop for battery.

c) Switch and contacts pole are not protected by the isolator.

d) Battery Spaces is not in good condition

e) There is a gap between battery spaces and refueling pipeline space. This condition could make a battery moving due to the motion of a vessel and the connector to the battery could be broken.

f) Brocken Socket

- Static electricity is indicating around the tank and hull.

- There is no earthing system on the tank and hull. Earthing at the tank is needed to prevent explosion or etc.

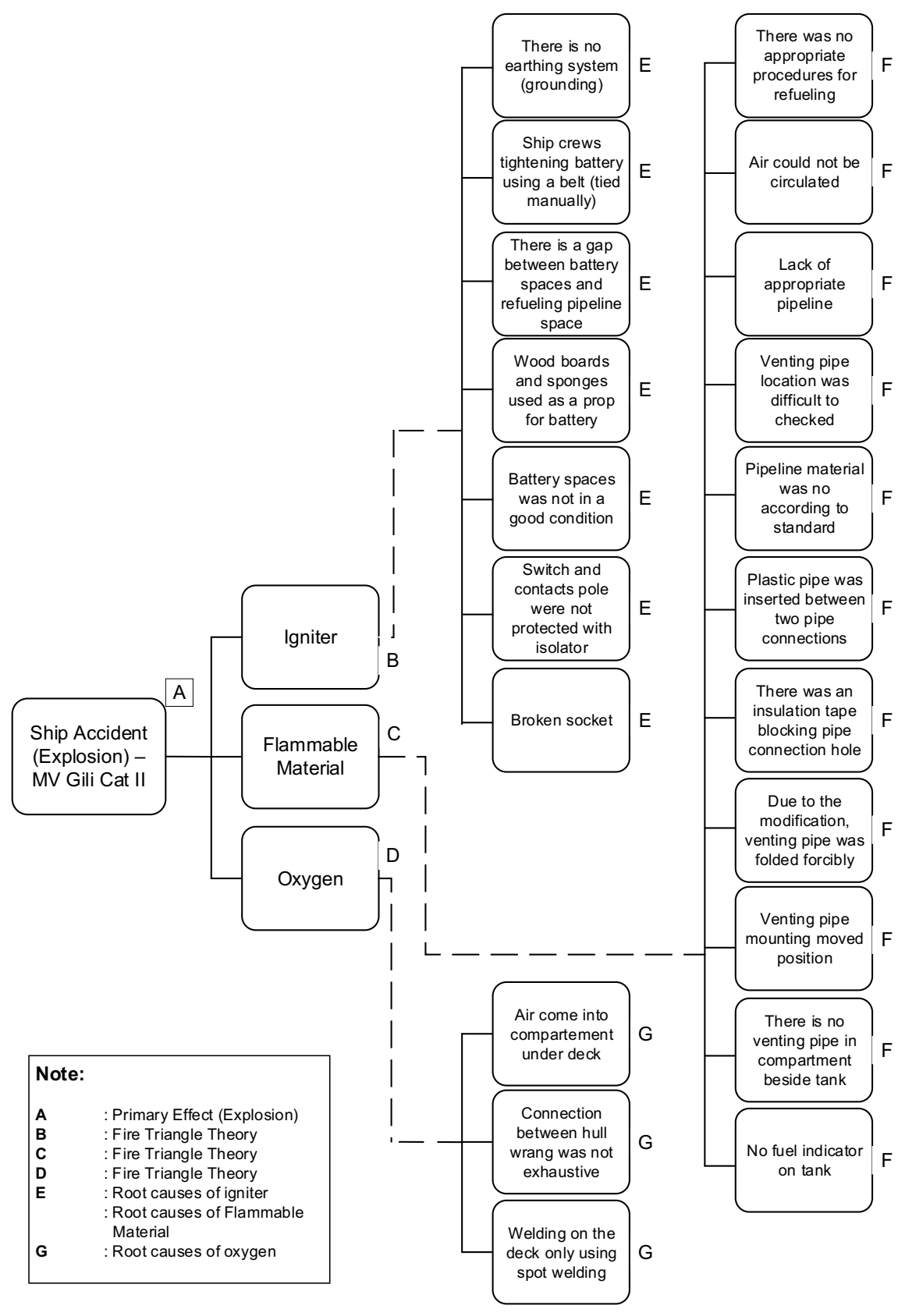

Figure 3: MV. Gili Cat II Explosion Root Cause Analysis 
2. Conditions that became the main cause of Flammable Material factor are:

- There is a fuel spill when refueling

- Refueling procedures

- Venting pipe system (design, condition, etc.) is not according to NCVS Ch. V

Based on the NTSC Investigation the main factor of flammable material is saturated gas of the fuel oil. Saturated gas estimated coming from fuel oil pipeline of engines and there is a fuel spill when refueling. MV. Gili Cat II was refueling manually and this condition is not in accordance with the standards. Refueling for fuel tanks capacity exceeding 10 liters shall not be used a gravity feed fuel (refueling manually) [6].

Based on NTSC investigation fuel pipelines and venting pipe were using the flexible fiber-type hose. It should be used a standard material such as SAE 30R9-Fuel Injection Hose MediumPressure Coupled and Uncoupled Synthetic Rubber Tube and Cover [6]. Saturated gas was accumulated in a compartment beside the tank. This saturated gas cannot release from compartment because ventilation system did not work well. It is because of venting pipe was not in good condition, venting pipe mounting position was moved, and lack of venting pipe in a compartment beside the tank. Venting pipe condition was folded, there was a plastic pipe inserted between two pipe connections, there was an insulation tape blocking the hole in the pipe connection.

The condition of the fuel pipeline was not in a good condition. Based on NTSC Investigation, pipe connector has been corroded and fuel pipe condition has been brittle. Those conditions are described in Figure 4 a) and b). Those conditions are caused by ship crew didn't check well and regularly and materials that do not accordance with standards. Venting pipe folded caused by venting pipe was not using standard material (flexible pipe) and venting pipe folded forcibly. The venting pipe mounting was located above the tank before fuel tank modification, then it moved to the side of the tank. This indicates that venting pipe mounting cannot be used in the original construction. Venting pipe holder that located on the side of the tank would make fuel flow into venting pipe when the tank is full. All conditions made saturated gas cannot release.

Saturated gas was coming from fuel oil pipeline for engines. Fuel oil for the engine was using a gasoline. The minimum concentration of a combustible gas or vapor necessary to support its combustion in air. It is defined as the Lower Explosive Limit (LEL) for that gas. Below this level, the mixture is too "lean" to burn. The maximum concentration of a gas or vapor that will burn in the air is defined as the Upper Explosive Limit (UEL). Above this level, the mixture is too "rich" to burn. The range between the LEL and UEL is known as the flammable range for that gas or vapor [7]. LEL and UEL for gasoline are $1.4 \%$ and $7.6 \%$. From the description above, if the capacity of the fuel tank is 15001 . Explosion can happen only if the fuel has been vaporized within $21-114$ liters.
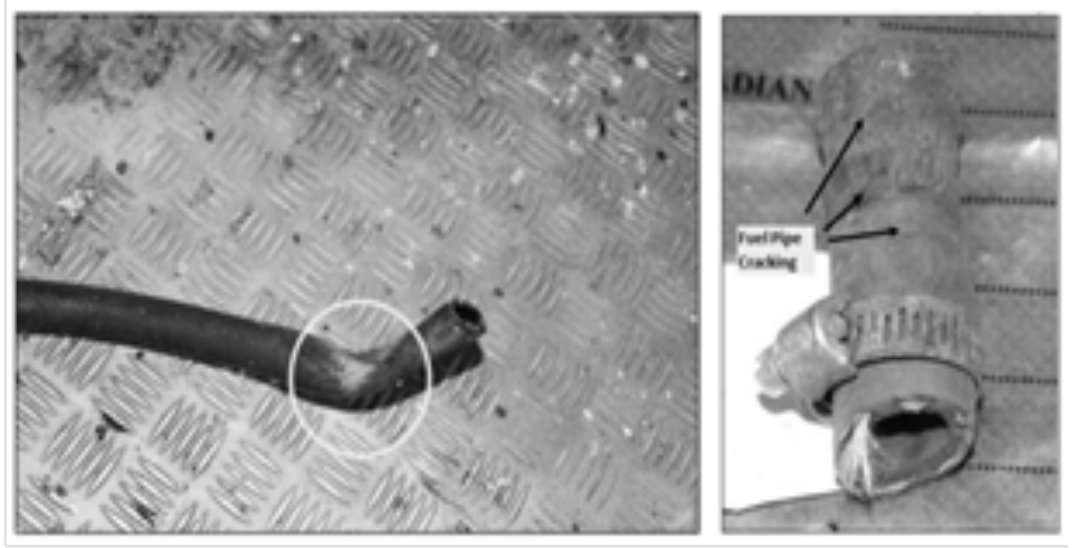
Figure 4: a) Venting pipe folded. b) fuel pipe cracking (brittle) [8]

3. Conditions that became the main cause of Oxygen factor are:

- The compartment below deck is not gastight

- Only using a spot welding

Evidence for there was only a spot welding on the deck is described in Figure 5. Compartment beside tank is not gastight, so there is an oxygen in it. There was some hollow point on the main deck, so this is an access for oxygen to entry to the compartment below the deck (explosion location). Based on NTSC investigation, connection hull and wrang was not exhaustive. This condition also becomes an access for oxygen to entry to the compartment.

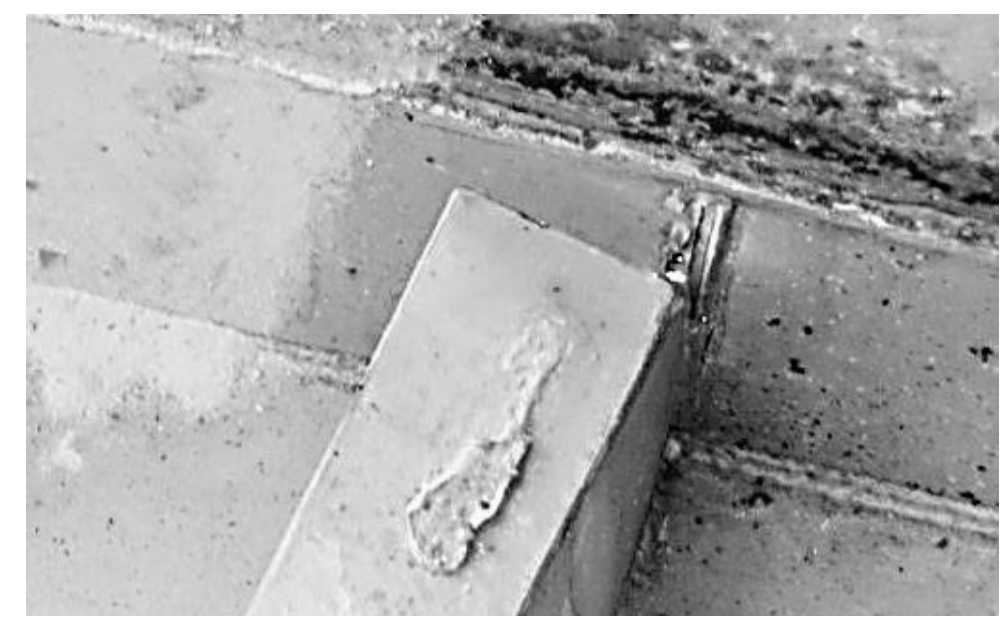

Figure 5: Spot welding on the deck [8]

\subsection{Electrical System Recommendation}

Recommendations on this system are according to NCVS Ch. V. Here are recommendations for the electrical system:

\subsubsection{General Electrical Requirements}

Electrical installations and parts of installations must be provided with isolation devices to prevent hazards associated with the abnormal operation (e.g. faults such as short circuits) and to allow maintenance of electrical equipment. Earthing system should be fitted with the electrical system. Cables and wiring system shall meet the requirements of IEC 60092-352 and IEC 60092-401.

Commissioning-inspection and testing shall be done due to modification, construction, or repairs the electrical system, equipment, or part. Those conditions shall be inspected tested in accordance with IEC 92-401 before being put into service.

\subsubsection{Extra-Low Voltage System and Batteries}

These rules are about the requirements for electrical equipment and electrical installations for extralow voltage systems. The battery that used only for starting engines. Engine starting cables shall be:

- Protected from mechanical damages; 
- Terminals protected from mechanical damages and from contacts with conductive materials;

- Be as short in length as with the starter motor batteries;

- Be routed to avoid the possibility of coming into contacts with flammable materials or sheathed with some material resistant to the effect of it;

- Be of adequate size for the expected cranking current and to minimize voltage drop;

- Be connected directly to the starter via the starting relay contacts; and

- Be suitably sealed at terminals in such a manner as to reduce corrosion.

Battery shall be controlled by an isolation switch operating in all active conductors. Isolation switches shall be located as close as practicable to the battery, and cables between the battery and isolating switch shall be double insulated or installed in a wiring enclosure throughout their entire length. Battery location and mounting shall be located as close as practicable to the engines they serve while minimizing the risk of hydrogen released by the battery being ignited by a spark from the starter motor. Mechanical protection is needed also.

Battery boxes shall be mounted and arranged to prevent movement of the battery cause the motion of the vessel. Battery boxes also shall be using chemical resistant materials. Ventilation for battery and battery compartment is needed to avoid the accumulation of hazardous gases. The accumulation of hazardous gases can cause a risk of fire or explosion, so battery compartments, rooms, and boxes shall be ventilated.

\subsection{Fuel Oil System Recommendation}

Recommendations on this system are according to NCVS and NFPA. Here are recommendations for fuel oil system:

\subsubsection{Fuel Tank Design Recommendation}

Fuel tank design recommendation is created to prevent the similar cases. The differences of this design with the previous design are venting system of the tank, tank earthing to prevent static electricity, baffle on the tank, and refueling using a pump. Fig. 6 and Fig. 7 is the comparison between the existing fuel tank design and the recommendation fuel tank design by following NCVS Ch. V.

Fuel pump for this recommendation is using HAINA PUMPS, type CYB-S-25-27, model YB801-2. The capacity and the head of the pump are $3 \mathrm{~m} 3 / \mathrm{h}$ and $27 \mathrm{~m}$.

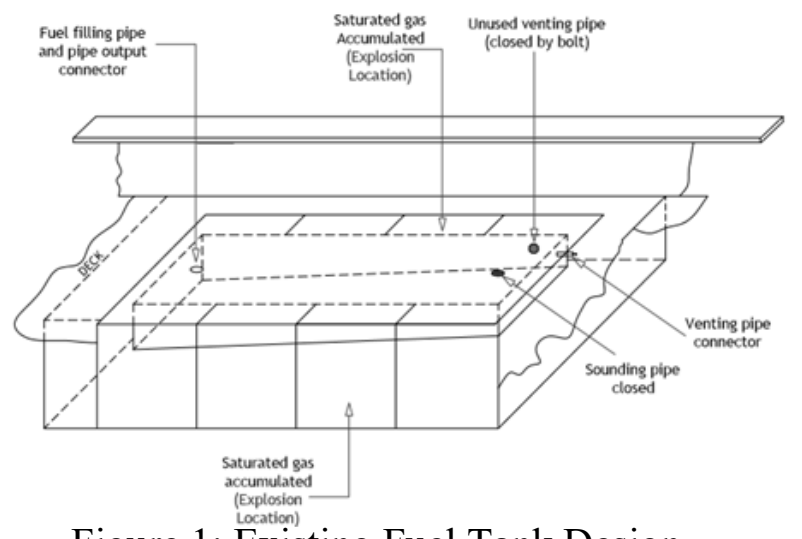

Figure 1: Existing Fuel Tank Design 


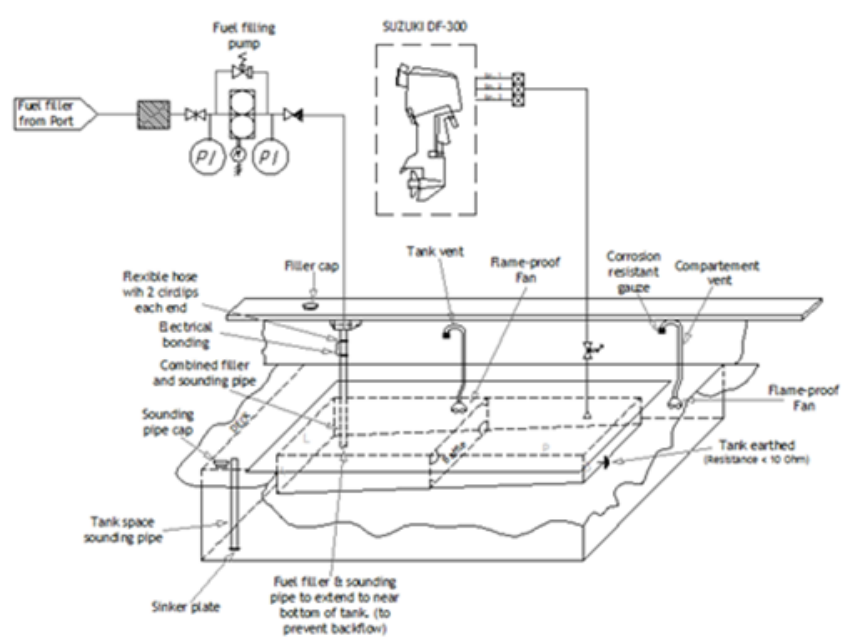

Figure 7: Recommendation Fuel Tank Design

\subsubsection{Fuel Tanks}

Fuel tank should not leak, be placed in a safe space. Construction of fuel intake, refueling lines, and venting pipe should be designed well (free from danger). The location of a tank is rear with the passenger cabin. MV. Gili Cat II is a small vessel, so tank placement like that cannot be avoided. There are recommendations for fuel tanks location. Fuel tank location shall not be fitted over stairways and ladders, over hot surfaces, over electrical equipment, and in any location near a source of ignition.

There are some recommendations for venting pipe. The tank shall be vented into the open air. Area of the venting pipe shall not be less than 1.25 times the area of the filling pipe if the tank is filling affected by the pump. The pipe shall terminate in a gooseneck on the open deck. Where the diameter of the pipe outlet exceeds $18 \mathrm{~mm}$, a corrosion-resistant wire gauze screen shall be fitted. A short flexible section of the hose length no more than $760 \mathrm{~mm}$ may be incorporated into the vent pipe for vibration damping or to facilitate installation. Pipe shall be made of reinforced synthetic rubber of a type resistant to fuel, salt water, and vibration. The flexible section of hose shall be fastened to the rigid section of the vent with two corrosion-resistant clips at each end. The material should be used a standard material such as SAE 30R9-Fuel Injection Hose Medium-Pressure Coupled and Uncoupled Synthetic Rubber Tube and Cover.

Existing refueling procedures on board was manual, so the recommendation is using a fuel pump. There are some safety arrangements for power-operated fuel pumps and motors. Relief valve and stop valve should be used. Relief valve discharging back to the suction side of the pump shall be fitted, if the closed discharge pressure exceeds the maximum design working pressure of the discharge system. Stop valves shall be fitted on the suction and discharge lines of cargo oil, fuel transfer, and fuel pressure pumps.

Means of stopping and fuel filters are should be fitted in fuel pump also. The remote fuel transfer pump or cargo oil pump shut-down arrangements shall be capable of operating when exposed to flame and heat from a fire within the space containing the pump.

\subsubsection{Additional requirements for fuel system}

For fuel filler pipe, the fuel filler pipe for non-portable fuel tanks shall extend to a point close to the bottom of the tank. It used to reduce the backflow of inflammable vapors through the filling pipe. 
Fuel pipe filler extends to a point close to the bottom is used for preventing static electricity when refueling also. Tanks shall be earthed so that resistance to earth is less than $10 \mathrm{ohms}$.

\subsubsection{Refueling Safety tips based on NFPA}

Refueling procedures for the vessel should be done safely. Another recommendation regarding the refueling procedures is following safety tips when refueling based on NFPA [9].

\section{Conclusion}

The root cause of the MV. Gili Cat II explosion is caused by many factors. Factors that can cause an igniter of the explosion are bad electrical wiring system, static electricity around the tank and hull, and there is no earthing system of the vessels. Conditions that cause a flammable material factor of the explosion are there was a fuel spill when refueling; refueling procedures did not safe; venting pipe system (design, condition, etc.) was not following NCVS Ch. V requirement and using inappropriate materials. Conditions that are the main cause of Oxygen factor are compartment below deck was not gastight and only using a spot welding. The following recommendations that related to the Electrical system are cable and wiring systems shall meet the requirements of IEC 60092-352 and IEC 60092-401. Earthing system shall be fitted. Batteries should be located as near as with the engines. The battery should be protected from short circuit, mechanical protection, and overload and installed properly to prevent movement of the battery.

The tank shall be vented into the open air. The pipe shall terminate in a gooseneck on the open deck. A short flexible section of the hose length no more than $760 \mathrm{~mm}$ can be used for venting pipe and filling pipe. The material of flexible pipe is using SAE J 30 or equivalent. Using an appropriate pump for filling the tank. Tanks should be earthed. Refueling procedures are following "Refueling safety tips based on NFPA".

\section{References}

[1] NTSC, "NTSC Accidents Data ", NTSC Accidents Data Year 2007 - March 2017 ed. Jakarta: Ministry of Transportation, 2017.

[2] NTSC, "MV. Gili Cat II Accident Report," Ministry of Transportation, Jakarta2016.

[3] D. L. Gano. (2011). RealityCharting Seven Steps to Effective Problem-Solving and Strategic for Personal Success.

[4] R. Gunawan, "Leak Causes Analysis in The Engine Room of KM. Nusantara Akbar," International Journal of Marine Engineering, vol. Vol. II, 2017.

[5] ARMS. (2017, March 23). Apollo Root Cause Analysis Introduction Final. Available: http://www.apollorootcause.com/about/apollo-root-cause-analysis-method/

[6] M. o. Transportation, "NON-CONVENTION VESSEL STANDARD INDONESIAN FLAGGED," in CHAPTER V MACHINERY \& ELECTRICAL, ed. Jakarta: Ministry of Transportation, 2009.

[7] NFPA, "Guide for Fire and Explosion Investigations," in 921, ed. America: NFPA, 2004.

[8] NTSC, "MV. Gili Cat II Survey Report," Ministry of Transportation, Jakarta2017.

[9] NFPA, "Public Education. Service station safety tips, " ed, 2016. 